\title{
A DIMENSÃO JURÍDICO-INSTITUCIONAL DA POLÍTICA PÚBLICA DA REGULARIZAÇÃO FUNDIÁRIA URBANA DE INTERESSE SOCIAL E A BUSCA DE SUA EFETIVIDADE ${ }^{1}$
}

\section{THE LEGAL-INSTITUTIONAL DIMENSION OF THE PUBLIC POLICY OF THE URBAN LAND REGULARIZATION OF SOCIAL INTEREST AND THE SEARCH FOR ITS EFFECTIVENESS}

\author{
RAFAEL TARANTO MALHEIROS ${ }^{2}$ \\ Clarice SEIXAS DUARTE ${ }^{3}$
}

RESUMO: A Constituição Federal de 1988 consagra o direito social à moradia, aí positivado em face da marcha desordenada que se deu, no país, do campo para as cidades, principalmente no século $X X$, que levou à inevitável degradação da urbe brasileira; apesar da previsão, o problema persiste, em escala nacional. Paralelamente, e diante da escassez de recursos públicos para prover o direito subjetivo a um lugar para morar, o que há são os deveres estatais de criar políticas públicas habitacionais e de prover recursos para tanto, decisões eminentemente políticas. Assim, tema cuja abrangência não se circunscreve, na busca de sua efetividade jurídico-social, a componentes jurídico-legais, para que seja adequadamente compreendido, demanda estratégia diversa daquela utilizada para questões de Direito tradicionais. Nessa investigação, utilizar-se-á o "Quadro de Referência de Políticas Públicas" (BUCCI, 2015) para análise de uma das políticas habitacionais, qual seja, a da regularização fundiária urbana de interesse social e sua novel conformação, dada pela Lei no 13.465, de 2017, e como o Poder Judiciário pode atuar sobre seu desenho institucional, o que afasta, pois, a presente pesquisa, da tradicional abordagem de questões ligadas ao mínimo existencial/reserva do possível.

PAlavras-Chave: Moradia; Políticas públicas; Regularização fundiária de interesse social; Regulamentação administrativa; Quadro de referência.

\footnotetext{
${ }^{1} \mathrm{O}$ presente trabalho tem como base estudos desenvolvidos na disciplina "Políticas Públicas", ministrada no Programa de Pós-Graduação em Direito Político e Econômico da Universidade Presbiteriana Mackenzie, e a dissertação de Mestrado de um de seus Autores: Malheiros (2019).

2 Mestre em Direito Político e Econômico pela Universidade Presbiteriana Mackenzie (Brasil). Contato: rafaelmalheiros2002@yahoo.com.br. Currículo: http://lattes.cnpq.br/9821659298737785.

${ }^{3}$ Professora Doutora do Programa de Pós-Graduação Stricto Sensu em Direito Político e Econômico da Universidade Presbiteriana Mackenzie (Brasil). E-mail: clarice.duarte@mackenzie.br. Currículo: http://lattes.cnpq.br/3035111705789712.
} 
ABSTRACT: The Federal Constitution of 1988 enshrines the social right to housing, which is positivized by the disorderly march that took place in the country from the countryside to the cities, especially in the 20th century, which led to the inevitable degradation of the Brazilian city; despite the prediction, the problem persists on a national scale. At the same time, and given the scarcity of public resources to provide the subjective right to a place to live, there are state duties to create public housing policies and provide resources for it, eminently political decisions. Thus, in view of a topic whose scope is not limited to legal components, in order to be adequately understood, it demands a strategy different from that used for traditional legal issues. In this investigation, the "Public Policy Reference Framework" (BUCCI, 2015) will be used to analyze one of the housing policies, that is, the urban land regularization of social interest and its novel conformation, given by No. 13,465 Statute, of 2017, and how the Judiciary can act on its institutional design, which removes, therefore, the present research, from the traditional approach of questions related to the existential minimum/reserve of the possible.

KEYWORDS: Public policies; Land regularization of social interest; Administrative regulations; Reference framework.

\section{INTRODUÇÃO}

A Constituição Federal de 1988 consagra, desde a publicação da Emenda Constitucional $\mathrm{n}^{\mathrm{o}} 26$, de 2000 , em seu art. $6^{\circ}$, o direito social à moradia, consectário de seus fundamentos relativos à cidadania e à dignidade da pessoa humana, inscritos em seu art. 1 , incs. II e III.

A concretização deste direito, todavia, não é realizada de forma satisfatória. A urbanização do país se deu de forma desorganizada. Em face de uma teia de políticas públicas inapropriadas ou ausentes, multiplicaram-se as irregularidades, como, p. ex., loteamentos clandestinos e invasão de áreas públicas e privadas.

Em tentativa de contornar o quadro, e em face da deferência estabelecida na $\mathrm{CF} / 88$ à função social da propriedade e ao próprio direito à moradia, edita-se, em 2001, a Lei no 10.257, conhecida como "Estatuto da Cidade" (EC), regulamentando os arts. 182 e 183 da Constituição. Já se tratava, aí, de se fixar diretrizes gerais de política urbana, a fim de corrigir problemas decorrentes da urbanização desordenada.

Dentre as diretrizes do EC, figura em seu art. 20, inc. XIV, a da efetivação da regularização fundiária. Esta pressupõe, sinteticamente, três aspectos: (i) dimensão urbanística, a partir do investimento para melhoria das condições de vida da população; (ii) dimensão jurídica, com instrumental que possibilite a aquisição da propriedade em áreas privadas e o reconhecimento da posse em áreas públicas; e 
(iii) dimensão registrária, com lançamento nas matrículas imobiliárias da aquisição de tais direitos.

De molde a superar os percalços existentes de modo adequado, veio à luz a Lei no 11.977, de 2009, pormenorizando, em relação à previsão genérica do Estatuto da Cidade, o tratamento da regularização fundiária urbana. Em 22 de dezembro de 2016, publicou-se a Medida Provisória (MPV) no 759, revogando-se aquela norma e as demais relacionadas à regularização fundiária. Em 11 de julho de 2017, publicouse a Lei no 13.465 , trazendo uma série de novidades sobre o assunto, inclusive em relação à MPV que lhe deu origem.

A nova Lei, que tratou das Regularizações Fundiárias Rural e Urbana (Reurb), definiu esta, em seu art. 9ㅇ, como a que "abrange medidas jurídicas, urbanísticas, ambientais e sociais destinadas à incorporação dos núcleos urbanos informais ao ordenamento territorial urbano e à titulação de seus ocupantes". Trouxe, em seu art. 13, a Reurb de Interesse Social (Reurb - S), objeto deste trabalho, "aplicável aos núcleos urbanos informais ocupados predominantemente por população de baixa renda, assim declarados em ato do Poder Executivo municipal".

Da leitura do retro citado art. 9o, emergem três concepções para o conceito de "regularização fundiária urbana", um amplo e dois restritos ${ }^{45}$. À acepção ampla, primeira parte do dispositivo legal, estariam vinculados os elementos do conceito normativo. À primeira acepção estrita, "incorporação dos núcleos urbanos informais ao ordenamento territorial urbano", estariam vinculados os conceitos relacionados à regularização urbanística, a abranger, por exemplo, a disponibilização de serviços essenciais. Já à segunda acepção, de "titulação dos ocupantes", enfoque deste artigo, estaria relacionada a obtenção de títulos por parte dos moradores dos lugares onde se promovem os processos de regularização, sejam de propriedade ou de posse.

Sendo certo que tais ordens possuem autonomia teórica, também é certo que devem ser efetivadas de maneira vinculada. Para tanto, deve-se fornecer adequada base institucional, centrada em que se compatibilizem os fatos ocorrentes com os mecanismos jurídicos bastantes.

No âmbito da racionalidade estatal, quanto ao procedimento, intentou-se simplificá-lo, em âmbito administrativo. No Estado de São Paulo, a CorregedoriaGeral do Tribunal de Justiça editou os Provimentos - meios de controle preventivos da regularidade da prestação judicial e extrajudicial - de noํs 18, de 2012; 25, de 2012; 16, de 2013; e 21, de 2013, todos no intuito de desburocratizar o procedimento onde possível, ainda quando vigorava a Lei $n^{\circ} 11.977$, de 2009. Na vigência da Lei ${ }^{\circ}$ 13.465, de 2017, em 19 de dezembro de 2017, editou-se, de modo pioneiro ${ }^{6}$, o Provimento CGJ no 51/2017, com o mesmo móvel dos anteriores.

${ }^{4}$ Luft (2014, p. 27-45).

${ }^{5}$ Alfonsin (2008, p. 16-21).

${ }^{6}$ Malheiros (2019, p. 138-141). 
Em face de um problema que acomete grande parte cidades brasileiras, cujo déficit habitacional e inadequação fundiária montavam, em 2015, conforme dados do último estudo realizado pela Fundação João Pinheiro, a 8,16\% (oito vírgula dezesseis por cento) e 3,2\% (três vírgula dois por cento) das habitações urbanas, perfazendo o total, respectivamente, de 5.572 .000 (cinco milhões, quatrocentos e quatorze mil e oitocentos) e de 1.871 .000 (um milhão, oitocentos e setenta e um mil) domicílios $^{7}$, apresenta-se, neste trabalho, como a regulamentação administrativa da legislação pertinente à regularização fundiária urbana pode auxiliar a promover, com celeridade e segurança, a cidadania e a inserção social de seus beneficiários.

A relevância do presente artigo, portanto, funda-se no fato de expor como a edição da Lei no 13.465 , de 2017, no que pertine à regularização fundiária urbana de interesse social, e à regulamentação administrativa conferida ao assunto pela Corregedoria-Geral do Tribunal de Justiça do Estado de São Paulo pode contribuir par o exercício da cidadania, naquilo que respeita ao direito social de moradia.

Para tanto, utilizar-se-á o "Quadro de Referência de Políticas Públicas", que “[...] aponta os elementos principais que permitem compreender sua organização interna, a partir da base jurídica, identificando as ligações com aspectos políticos, econômicos e de gestão mais importantes", com "[...] ênfase ao aspecto institucional das políticas públicas" 8

A hipótese desta pesquisa é de que a regulamentação administrativa da legislação pertinente à regularização fundiária é um meio eficaz (eficácia jurídicoformal) para alcançá-la, apto a promovê-la com celeridade e segurança jurídica, adequando os princípios que regem a atividade registral à interpretação sistemática que se confere à Constituição Federal, com fim de promover a inserção social dos beneficiários, perseguindo sua efetividade (eficácia social).

Quanto à metodologia aplicada, este trabalho se delimitará a abordar tão somente assuntos pertinentes à regularização fundiária urbana. Levará em conta, para tanto, dentre outras matérias relevantes, a relação do direito privado com a informalidade dos assentamentos, bem como o contexto político-jurídico que ensejou a edição da nova Lei.

Quanto às limitações, as normativas administrativas em exame serão restritas ao quanto expedido pela Corregedoria-Geral do Tribunal de Justiça do Estado de São Paulo.

\section{REgULARIZAÇÃo FUNDIÁRIA URBANA}

Em perspectiva histórica, o crescimento dos grandes núcleos urbanos brasileiros, ao longo da segunda metade do século XX, caracterizou-se pela configuração de duas cidades distintas: uma legal, consolidada pela

\footnotetext{
7 Fundação João Pinheiro (2018, p. 21-31; 51).

${ }^{8}$ Bucci (2015, p. 01-02).
} 
implementação de parcelamentos oficiais (legalizados) localizados, em geral, em áreas mais centrais, destinados à moradia das classes média e alta; e uma cidade ilegal, destinada à moradia das classes baixas, qualificada pela implantação de loteamentos ilegais (ou irregulares) nas porções periféricas dos municípios e/ou pela consolidação de favelas em diversas áreas das regiões mais centrais9. Este processo, como não poderia deixar de ser, foi acompanhado pela demanda por moradias.

$\mathrm{Na} \mathrm{CF} / 88$, a proteção ao direito à moradia está definitivamente expressa desde o ano 2000, quando a Emenda Constitucional no 26 incluiu a habitação no rol dos direitos sociais definidos em seu art. $6^{\circ}$. Deve ser interpretado em suas duas dimensões, quais sejam: i) positiva, que se trata do dever do poder público de implementar uma política de habitação de interesse social; e ii) negativa, que implica em se abster de promover deslocamentos involuntários de população carente, cuja situação pode ser regularizada nos locais que ocupam ${ }^{10}$.

A moradia é direito que integra e limita o direito de propriedade. Não são incompatíveis, mas há situações, no âmbito das políticas urbanas e habitacionais, em que entram em conflito, e a preponderância de um deles só pode ser estabelecida no caso concreto. Na questão da titulação dos moradores, regularização fundiária stricto sensu, a moradia pressupõe posse - cuja noção histórica identifica a necessidade de o homem dominar um espaço -, não propriedade $^{11}$.

Diga-se que, mesmo em face da hegemonia histórica da visão proprietária, o cenário está se ampliando para a utilização de outros institutos jurídicos que não são propriedade stricto sensu, mas que se mostram, jurídica e faticamente, mais viáveis, pois convivem com situações que impossibilitam ou dificultam a apropriação privada, como os casos de legitimação da posse.

Aqui, exsurge o princípio da função social da propriedade, permitindo a compatibilização entre o direito individual e os interesses coletivos ${ }^{12}$. Confere ao Estado o poder de obrigar os proprietários, exaltando "o papel promocional (da função social), de maneira que a disciplina das formas proprietárias e a sua interpretação deverão ocorrer de forma a garantir e promover os valores sobre os quais se funda o ordenamento"13, sem chegar ao extremo de coletivização dos bens, próprio de regimes socialistas ${ }^{14}$.

Intermediando as relações entre moradia e propriedade, tem-se outro instituto jurídico relevante, que é a posse. No âmbito das regularizações, objeto deste

\footnotetext{
9 D'Ottaviano, e Silva (2009, p. 204).

${ }^{10}$ Sarlet (2009, p. 21-22).

${ }^{11}$ Malheiros (2019, p. 16).

${ }^{12}$ Como assenta o $\S 1^{\circ}$ do art. 1.228 do Código Civil: “O direito de propriedade deve ser exercido em consonância com as suas finalidades econômicas e sociais [...]".

${ }^{13}$ Perlingieri (2008, p. 940).

${ }^{14}$ Hironaka (2016, p. 102).
} 
trabalho, o que se busca é a segurança da posse, e não, necessariamente, a propriedade. Os principais conflitos fundiários se travam entre os proprietários registrais, que normalmente não usam seus bens, e os possuidores/ocupantes que moram nos imóveis informalmente. Para garantir a segurança da posse nas operações de regularização fundiária é necessário enfrentar a questão e definir os direitos que devem prevalecer ${ }^{15}$. Face à discussão, adota-se a visão da doutrina jurídica que trata da posse como direito autônomo à propriedade ${ }^{16}$.

Para caracterizar a informalidade de um assento, pelo menos uma destas características deve se verificar: (i) ocupação de terras públicas, seguida de autoconstrução; (ii) subdivisão não autorizada de terras públicas, seguida pela venda dos lotes individuais e de autoconstrução; (iii) projetos habitacionais populares irregulares; (iv) urbanização e desenvolvimento de áreas definidas como rurais; (v) subdivisão não autorizada de lotes previamente existentes juridicamente, destinados à construção de edifícios adicionais; (vi) ocupação generalizada das margens dos rios; (vii) ocupação de espaços públicos como ruas, calçadas e viadutos ${ }^{17}$. Intentando contornar o problema, a legislação urbanística o agravou, ao estabelecer padrões rigorosos dentro de normas técnicas de habitabilidade, esquecendo de parcela da população residente em moradias precárias. Tal se verifica desde o tempo em que vigia o regime sesmarial, passando pela "Lei de Terras", de 1850, pelo Código Civil de 1916, desembocando na Lei de Parcelamento do Solo Urbano de 1979. Os loteamentos clandestinos, então, são guindados à opção de moradia, com sua aparência de proteção possessória, à vista de contrato celebrado entre loteador e adquirente, além da relativa modicidade do custo, vez que a gleba é desprovida de equipamentos públicos (irregularidade urbanística) e de atendimento às formalidades legais (irregularidade jurídica, dominial).

Com a promulgação da Constituição de 1988, estabelecem-se diretrizes políticas e jurídicas para a condução de políticas públicas urbanas e de proteção à moradia, definindo-se competências aos entes federados, onde se inserem a ações de âmbito nacional, regional e local. Inauguram-se novas linhas de crédito (ex.: programa "Carta de Crédito") e publicam-se leis concedendo subsídios ao estrato mais pobre da população (ex.: Lei no 11.124, de 2005). As iniciativas culminam na edição da Lei no 11.977, de 2009, instituindo o Programa Minha Casa, Minha Vida (PMCMV), com produção de novas unidades e requalificação das já existentes, além de aquisição de novos domicílios por parte do beneficiário final ${ }^{18}$.

\footnotetext{
${ }^{15}$ Malheiros (2019, p. 21).

${ }^{16}$ Enunciado CJF no 492: A posse constitui direito autônomo em relação à propriedade e deve expressar o aproveitamento dos bens para o alcance de interesses existenciais, econômicos e sociais merecedores de tutela.

17 Fernandes (2011, p. 10-11).

18 Malheiros (2019, p. 30-36).
} 
Todavia, apesar de seus méritos, o PMCMV não se preocupou com a questão fundiária, pois o objetivo do governo era dirigir o setor imobiliário para atender à demanda habitacional de baixa renda. O assunto ficou a cargo do Capítulo III da citada Lei, que tratou da regularização fundiária de assentamentos urbanos, "[...] instrumento de mais utilidade à população de baixa renda, vista a realidade brasileira, onde se concentra a maior parte do déficit habitacional" ${ }^{19}$, criando um vínculo estável entre morador e o bem, não significando, necessariamente, propriedade. Doutrina que influenciou sobremodo a Lei em comento assenta que

Regularização fundiária é um processo conduzido em parceria pelo Poder público e população beneficiária, envolvendo as dimensões jurídica, urbanística e social de uma intervenção que, prioritariamente, objetiva legalizar a permanência de moradores de áreas urbanas ocupadas irregularmente para fins de moradia e, acessoriamente, promove melhorias no ambiente urbano e na qualidade de vida do assentamento, bem como incentiva o pleno exercício da cidadania pela comunidade sujeito do projeto $^{20}$.

A Lei $n^{0}$ 11.977, de 2009, teve o mérito de concretizar previsão genérica do Estatuto da Cidade, tornando-se modo efetivo de acesso ao direito à cidade e à moradia, delimitando os tipos de assentamentos a serem regularizados e disponibilizando novos instrumentos para a regularização considerada de interesse social. Preencheu lacunas legais, trazendo, inclusive, um conceito de regularização fundiária e uma série de princípios, dando um passo na direção da concretude da função social da propriedade. Havia, por certo, espaço de melhora ${ }^{21}$.

Em 22 de dezembro de 2016, irrompe na ordem jurídica nacional a MPV no 759, revogando o Capítulo III da Lei no 11.977, de 2009. Ressalta, em seu "item 87" e seguintes, o "importante aspecto econômico que, também, serve à legitimação desta proposta de Medida Provisória". Não foi isenta de críticas, que culminaram com o ajuizamento, pelo Ministério Público Federal, de ação direta de inconstitucionalidade, que alega que a norma é "[...] destituída dos requisitos constitucionais de relevância e urgência", e, no mérito, "[...] choca-se com todas essas diretrizes constitucionais e legais: ressente-se de participação popular, não leva em conta planos diretores nem o licenciamento ambiental e urbanístico" 22 .

Ao cabo de estudos de prós e contras da MPV, convertida na Lei no ${ }^{\text {o }} 13.465$, de 201723, concluiu-se que

\footnotetext{
${ }^{19}$ Malheiros (2019, p. 37).

${ }^{20}$ Alfonsin (2007, p. 78).

${ }^{21}$ Malheiros (2019, p. 62).

22 Ministério Público Federal (2017, p. 11-13).

${ }^{23}$ Malheiros (2019, p. 64-73).
} 
O governo, iniciando o procedimento, em vez de aproveitar a experiência anterior e proceder a alterações pontuais, optou por renegá-la, revogando a norma então vigente, terminando por passar duas impressões: (i) de que quis deixar sua "marca" na questão fundiária brasileira; e (ii) de que este problema pode ser resolvido com a mera edição de nova lei, equívoco já evidenciado. Ao cabo, o trâmite legislativo manteve, basicamente, o sistema instituído em 2009, com resgate de institutos abandonados e atração de outros, visando potencializar a incorporação dos núcleos informais ao ordenamento territorial ${ }^{24}$.

Posto isto, e dado que a Lei $\mathrm{n}^{\mathrm{o}}$ 13.465, de 2017, norma geral que rege a regularização no país, encontra-se em vigor, é com base nela que se continuará o presente estudo.

\section{QUADRO DE REFERÊNCIA DE POLÍTICAS PÚBLICAS}

Neste tópico, discorre-se, de modo breve, sobre o citado "Quadro de Referência de Políticas Públicas", no que toca às suas inspiração e utilidade. Seus elementos, já aplicados ao móvel deste trabalho, serão apresentados, também de modo sucinto, no tópico seguinte.

O quadro, desenvolvido nos idos de 2013, é um dos esquemas de representação voltado à análise da organização jurídica de políticas públicas. Tem sua utilidade principal em auxiliar a demarcar de modo mais cristalino os limites de determinado programa de ação, permitindo que o pesquisador "[...] possa se debruçar sobre poucas questões jurídicas selecionadas" 25 .

Contribui para estabelecimento de um "[...] método estruturado da abordagem jurídica das políticas públicas", não de mérito, evitando que análises daí decorrentes não sejam sempre fraturadas, reiterativas, isoladas, prestante ao desenvolvimento de uma "tecnologia jurídica" acerca do assunto ${ }^{26}$.

Aborda as políticas públicas com visão jurídico-institucional, i.e., reúne o aspecto decisional com efeitos protraídos no tempo, com suas estratégias, regras e procedimentos, à estabilização do direito propriamente aplicado, ressaltando sua noção de poder organizado. Esta conexão entre elementos jurídicos e políticos rompe com o isolamento metodológico do Direito.

\footnotetext{
${ }^{24}$ Malheiros (2019, p. 73).

${ }^{25}$ Bucci (2019, no prelo).

${ }^{26} \operatorname{Bucci}(2015$, p. 02).
} 
Apresentados os fundamentos do "Quadro de Referência", pode-se desdobrar a locução jurídico-institucional em três principais componentes: (i) organização, abrangendo os elementos políticos do programa de ação e como se interrelacionam; (ii) papéis institucionais, o "quem faz o quê", despersonalizando a iniciativa; e (iii) finalidade, em seus sentidos político e social, atinente ao sucesso, ou não, da agregação de interesses fundantes do programa.

Enfim, espera-se, como produto da aplicação do Quadro, “[...] evolução na percepção de como se analisam e com o se organizam juridicamente as políticas públicas, induzindo a produção de uma nova cultura da gestão pública, em que a presença do direito seja mais integrada e prospectiva" ${ }^{27}$.

Neste trabalho, encontra sua aplicação, justamente, devido à multiplicidade de normas que sustentam o programa de ação sob exame ${ }^{28}$, no caso, a Lei oํ 13.465 , de 2017, seu Decreto regulamentador, de no 9.310, de 2018, e Provimento CGJ no 51/2017. Além disso, a regularização fundiária é tema tipicamente coletivo (i. e., não busca acertar cada situação dos moradores informais), em que os Poderes Executivo e Judiciário deveriam dialogar, impulsionando ações coordenadas ${ }^{29}$.

\section{REGULARIZAÇÃo FUNDIÁRIA URBANA E O QUADRO DE REFERENCIA}

Neste tópico, demonstra-se a aplicação do "Quadro de Referência", com seus componentes ${ }^{30}$, à regularização fundiária urbana de interesse social.

\section{Nome oficial do programa de ação: é sua marca política}

No caso, como visto, é a Reurb-S, conforme art. 9ํㅡㅁ Lei no 13.465, de 2017. Substitui o antigo termo "regularização fundiária de interesse social" - assim mesmo, por extenso -, da revogada Lei n 11.977 , de 2009.

\section{Gestão governamental: que criou o programa, identificando seu espectro político-partidário}

Criado no mandato do Presidente Michel Temer, inspirado em política do Banco Mundial ${ }^{31}$, como se vê do "Item 88" da Exposição de Motivos da MPV nº 759, de 2016, convertida na Lei no 13.465 , de 2017:

\footnotetext{
${ }^{27} \operatorname{Bucci}(2015$, p. 04-10).

${ }^{28} \operatorname{Bucci}(2015$, p. 06).

${ }^{29}$ Bucci $(2019$, no prelo).

${ }^{30}$ Bucci $(2015$, p. 5-9).

${ }^{31}$ Hernando de Soto (2001, p. 79-80), economista peruano que inspirou tal política, para quem "é a documentação de propriedade que fixa as características econômicas dos ativos para que possam ser usados nas garantias de transações comerciais e financeiras [...]. Para criar crédito e gerar investimento, o que as pessoas hipotecam não são os ativos físicos em si, mas suas representações
} 
o reconhecimento, pelo Poder Público, dos direitos reais titularizados por aqueles que informalmente ocupam imóveis urbanos, permite que estes imóveis sirvam de base para investimento do capital produtivo brasileiro, à medida que poderão ser oferecidos em garantia de operações financeiras.

\section{Base normativa: normas principal e acessórias que sistematizam o programa}

Principais: Constituição Federal, arts. 6º 182 e 183; Lei no 13.465, de 2017, arts. 90 a 54. Acessórias: Lei no 6.766, de 1979 (LPS); Estatuto da Cidade; Lei no 11.977, de 2009.

\section{Desenho jurídico-institucional: organização macro do programa}

Envolve (i) articulação entre União, Estados e Municípios (principais atores), com repasse de recursos e capacitação para os agentes destes entes e (ii) evolui do Cap III da Lei no 11.977, de 2009, alcançando todos os "núcleos urbanos" (Lei no 13.465, de 2017, art. 11, inc. I), com características urbanas, não mais, somente, os "assentamentos urbanos", localizados em "áreas urbanas".

Contemplam-se os núcleos clandestinos, irregulares ou aqueles nos quais, atendendo à legislação vigente à época da implantação ou regularização, não foi possível realizar a titulação de seus ocupantes, sob a forma de parcelamentos do solo, de conjuntos habitacionais ou condomínios, horizontais, verticais ou mistos. O “Item 81" da Exposição de Motivos da MPV nº 759, de 2016, convertida na Lei n⿳o 13.465, de 2017, explicita: "identificados os núcleos urbanos informais, pelo Poder Público, concluída a REURB, estes são juridicamente reconhecidos e, assim, tornam-se alvo de investimentos públicos, orientados, em última análise, à promoção da função social das cidades".

\section{Agentes governamentais: e suas competências, atribuições e responsabilidades}

Todos os entes governamentais podem requerer a Reurb-S (Lei $\mathrm{n}^{\mathrm{o}}$ 13.465, de 2017, art. 14, inc. I). As políticas de regularização fundiária demandam iniciativas urbanísticas e habitacionais, inserindo-se nas competências legislativas concorrentes $^{32}$ e nas materiais comuns ${ }^{33}$, motivo por que sua realização abrange ações dos três entes federados. Especificamente, e observando a predominância do interesse:

(i) União, (i.1) traçando a política geral, (i.2) capacitando agentes estaduais e municipais através do Ministério das Cidades, (i.3) franqueando acesso aos Estados

de propriedade - os títulos e ações registrados - regidos por leis que podem ser executadas em toda a nação".

${ }^{32}$ Constituição Federal, arts. 24 e 30.

${ }^{33}$ Constituição Federal, art. 30. 
de recursos financeiros para compensação de atos registrais (Lei no 11.124, de 2005, art. 11, § $4^{\circ}$ ) e aos Municípios de recursos para a regularização em si (Lei ㄲo 11.124, de 2005 , art. 11, inc. III e $\S 2^{\circ}$ );

(ii) Estados e DF, (ii.1) convênio com Municípios para capacitar órgãos ambientais (Lei $\mathrm{n}^{\mathrm{o}} 13.465$, de 2017 , art. $12, \S 1^{\circ}$ ), podendo substituí-lo neste mister ( $\left(4^{\circ}\right.$ ), (ii.2) criação de fundos específicos destinados à compensação, total ou parcial, dos custos referentes aos atos registrais (Lei no 13.465, de 2017, art. 73), (ii.3) através do Poder Judiciário e suas Corregedorias-Gerais da Justiça, emitem instruções às serventias imobiliárias, fiscalizando sua execução (art. 103-B, CF/88);

(iii) Municípios, (iii.1) avaliam o núcleo urbano informal (Lei no 13.465, de 2017, art. 11, inc. III), (iii.2) promovem a demarcação urbanística (Lei oํ 13.465, de 2017, art. 11, inc. IV), (iii.3) expedem a Certidão de Regularização Fundiária - CRF, listando os ocupantes do núcleo urbano informal regularizado, bem como os direitos reais que lhes foram conferidos (Lei no 13.465, de 2017, art. 11, inc. V), podendo reavaliar parâmetros urbanísticos (Lei no 13.465 , de 2017, art. 11, § $1^{\circ}$ ), (iii.4) instituem ZEIS (Lei oㅜ 13.465/17, art. 18), (iii.5) ... Protagonistas no procedimento (Lei no 13.465 , de 2017, arts. 28 a 34), elaborando o projeto de regularização (Lei oํ 13.465, de 2017, arts. 35 a 39$)$.

\section{Agentes não governamentais: indução de comportamentos/financiamentos}

Poderão requerer (Lei n⿳0 13.465, de 2017, art. 14) beneficiários, associações de moradores, organizações sociais e da sociedade civil que tenham por finalidade atividades ligadas ao assunto; proprietários de imóveis, incorporadores e loteadores, MP; Defensoria, ampliando o rol da Lei revogada.

Lacuna da Lei ao não prever normas de incentivo também ao setor privado financeiro de um modo geral, não vinculado ao sistema financeiro de habitação, com esquemas que pudessem atrair investimentos em áreas não regularizadas, mas regularizáveis. O tão-só reconhecimento de direitos reais provavelmente não bastará a que bancos venham a conceder créditos em montante maior do que se verifica, ou o concederão a taxas de juros mais elevadas, visando contornar o risco da operação ${ }^{34}$.

\section{Mecanismos jurídicos de articulação: forma federativa e a repartição de competências}

A CF/88 atribui competência comum a todos os entes para "promover programas de (...) melhoria das condições habitacionais (art. 23, inc. IX); e 24, I, competência concorrente de União e Estados, "legislar sobre direito (...) urbanístico" (art. 24, inc. I), que inspira, por exemplo, a aprovação, por parte dos Estados, de loteamentos em determinadas condições (Lei nº 6.799, de 1979); no art. 182, § 4º , “É facultado ao

${ }^{34}$ Pinto (2017). 
Poder Público municipal, mediante lei específica para área incluída no plano diretor, exigir, nos termos da lei federal [Estatuto da Cidade, Lei no 10.257, de 2001], do proprietário do solo urbano não edificado, subutilizado ou não utilizado, que promova seu adequado aproveitamento, sob pena, sucessivamente, de: (...)"

Uma lacuna que se apontou e sobre o qual se fez estudo mais aprofundado ${ }^{35}$ foi a falta de sintonia entre a Lei de Registros Públicos (Lei no 6.015, de 1973 - LRP) e projetos de regularização fundiária municipais. $\mathrm{O}$ assunto será retomado adiante.

\section{Escala e público-alvo: alcance esperado}

Público alvo é a população de baixa renda, conforme Lei no 13.465, de 2017, art. 13, inc. I; e Dec. no 9.310, de 2018, art. 6o , que assim dispõe: "Para a classificação da Reurb na modalidade Reurb-S, a composição ou a faixa da renda familiar para definição de população de baixa renda poderá ser estabelecida em ato do Poder Público municipal ou distrital, consideradas as peculiaridades locais e regionais de cada ente federativo. Parágrafo único. A renda familiar prevista no caput não poderá ser superior ao quíntuplo do salário mínimo vigente no País".

A escala pretendida é de 3,6 milhões de imóveis e 14 milhões de pessoas beneficiárias (Programas "Papel Passado" + "PAC/OGU"), conforme solicitações recebidas pelo Ministério das Cidades, de 2013 a 2016, não regularizados conforme Lei revogada ${ }^{36}$.

\section{Dimensão econômico-financeira: investimento, custeio ou pessoal}

Recursos financeiros do Fundo Nacional de Habitação de Interesse Social (Lei $\mathrm{n}^{\mathrm{o}}$ 11.124, de 2005), para assessoria e consultoria técnica e levantamento de dados; serviços cartográficos; aperfeiçoamento de pessoal; produção de material de divulgação etc. No ano de 2018, por exemplo, foi repassado a Estados, Distrito Federal e Municípios, referente ao programa orçamentário "1128 - Urbanização, Regularização Fundiária e Integração de Assentamentos", o montante de R\$ 10.792.393,56, a título de "Valor Restos a Pagar Pagos"37.

Constituído por (i) Fundo de Apoio ao Desenvolvimento Social (FAS), (ii) Orçamento Geral da União (OGU), (iii) empréstimos para programas habitacionais, (iv) receitas obtidas com recursos do Fundo etc.

10. Estratégia de implantação: refere-se às fontes oficiais e às reações esperadas

A implementação se verifica na seguinte forma: (i) formação de Grupo de Trabalho ("Rumos da Política Nacional de Regularização Fundiária"); (ii) novas ferramentas de apoio aos Municípios (ex.: sistema de informação georreferenciado); (iii) capacitação e apoio técnico; (iv) repasse de recursos; (v) trabalho com a SNH para melhoria habitacional e implantação de infra nos núcleos regularizados; (vi) revisão

\footnotetext{
${ }^{35}$ Malheiros (2019, p. 132ss).

${ }^{36}$ Brasil (2017).

${ }^{37}$ Controladoria-Geral da União (2019).
} 
do marco legal: "Item 86" da Exposição de Motivos da MPV nº 759, de 2016, convertida na Lei no 13.465, de 2017: “o modelo da REURB ora proposto em caráter substitutivo, para além de preencher lacunas deixadas pelo legislador, vem dinamizar e simplificar - inclusive sob uma perspectiva registral - o processo da regularização fundiária urbana no País, permitindo que este efetivamente alcance os seus fins".

As Prefeituras (principalmente, mas não só) determinam a modalidade de regularização (Reurb-S/Reurb-E). Reurb-S tem gratuidade dos atos registrais. Ato único de registro. Feita em larga escala (titulação coletiva, Lei no 13.465, de 2017, art. $44, \S 1$, inc. III, in fine: "(...) dispensada a apresentação de título individualizado".

Exemplificativamente, como reações esperadas, pode-se citar ataques especulativos com sinalização da regularização (versus ZEIS, "parcela de área urbana instituída pelo plano diretor ou definida por outra lei municipal, destinada preponderantemente à população de baixa renda e sujeita a regras específicas de parcelamento, uso e ocupação do solo", Lei n⿳⺈ 13.465, de 2017, art. 18, § $1^{1}{ }^{38}$.

\section{Funcionamento efetivo do programa: comparação com documentos externos à Administração}

No âmbito do Estado de São Paulo, a Corregedoria-Geral da Justiça, por meio de seu mencionado Provimento CGJ/SP no 51/2017, fez constar, nas Normas de Serviço do Extrajudicial, o Cadastro de Regularização Fundiária Urbana, “[...] destinado ao cadastramento dos projetos de regularização fundiária registrados nas unidades de registros de imóveis do Estado de São Paulo" (Item 403). Pode ser acessado, de modo gratuito, no sítio da Central Registradores de Imóveis ${ }^{39}$. Por exemplo, do período que se estende de 25/03/2009 (data da edição da MPV no 459, de 2009, convertida na Lei n⿳⺈ 11.977, de 2009) até os dias que correm:

\footnotetext{
${ }^{38}$ Samora (2013, p. 03-10).

${ }^{39}$ Disponível em: < https://www.registradores.org.br/RF/frmGraficos.aspx?from=U >. Acesso em: 7 maio 2019.
} 
Figura 1: Quantidade de regularizações no Estado de SP entre 25/03/2009 e 07/05/2019 Quantidade de Regularizaçốes

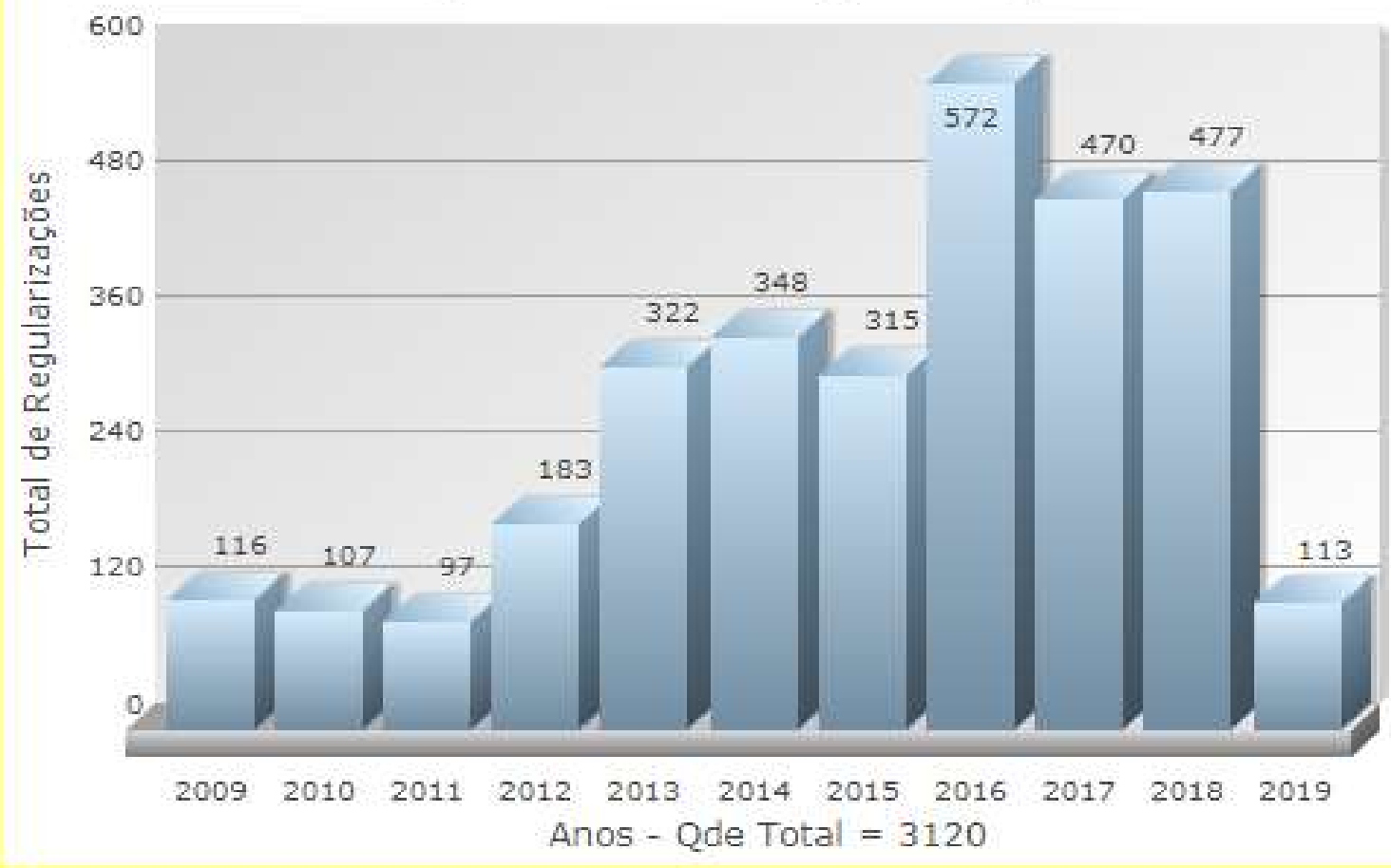

Fonte: Central Registradores de Imóveis

\section{Aspectos críticos do desenho: elementos jurídicos}

Como se disse, vertente das mais valiosas do quadro, permite destaque de ponto particular que mereça aprofundamento de seu estudo.

No caso, identificou-se que o sistema registral brasileiro, centrado nos princípios da legalidade, continuidade e especialidade, estaticamente interpretados, não atendem aos princípios da regularização fundiária. Para tanto, devem ser tomados de modo dinâmico, sem comprometer sua segurança. No próximo tópico, verificase o auxílio que a Corregedoria-Geral da Justiça paulista prestou neste sentido.

\section{REGULARIZAÇÃO FUNDIÁRIA E ATUAÇÃO ADMINISTRATIVA}

\section{Princípios registrais e sua coesão dinâmica na regularização fundiária urbana}

Vista a necessidade de cooperação entre os Poderes e os entes federativos para persecução da efetividade do direito posto e retomando o quanto exposto no tópico referente à regularização fundiária, em que se apontou o caráter principiológico da função social da propriedade urbana, diga-se que o fato de os procedimentos aptos a atingi-la não estarem regulamentados não se converte em óbice que possa ser 
oposto ao Poder Judiciário, garante dos direitos fundamentais, no desenvolvimento de suas atividades.

Também, retome-se a ideia, posta no fim do tópico anterior, de que legislação prejudica, em alguma medida, a efetivação da regularização fundiária ${ }^{40}$. O operador do Direito deve lidar com uma série de leis editadas em décadas diferentes (Lei de Registros Públicos e Lei do Parcelamento do Solo Urbano, editadas na década de 1970; Constituição Federal, editada na década de 1980; Estatuto da Cidade, editado na década de 2000; Lei no 13.465 , editada na década de 2010 etc.), para atender contextos sócio-políticos distintos, gerando dificuldades em sua interpretação.

Pois bem. Neste ponto, devem-se definir os princípios do registro de imóveis, elencados anteriormente, que, não obstante necessários à segurança jurídica, podem ser vistos como obstáculos a serem transpostos, e como podem ser flexibilizados, tendo por fim o alcance da regularização fundiária.

O princípio da legalidade deve funcionar "[...] como um filtro que, à entrada do registro, impeça a passagem de títulos que rompam a malha da lei, quer porque o disponente careça da faculdade de dispor, quer porque a disposição esteja carregada de vícios ostensivos"41. Assim, apresentado um título, o registrador imobiliário deve qualificá-lo, tendo em conta a legislação registrária, atendo-se somente aos aspectos formais (extrínsecos, v.g., se foi expedido por quem tem competência para tanto etc.), sem adentrar o mérito do título e negar vigência a normas dos entes federados, atribuição do Poder Judiciário quando em exercício de sua função jurisdicional. Verifica, assim, a aptidão de seu ingresso no fólio real.

O princípio da continuidade, "que se apoia no de especialidade, quer dizer que, em relação a cada imóvel, adequadamente individuado, deve existir uma cadeia de titularidades à vista da qual só se fará a inscrição de um direito se o outorgante dele aparecer no registro como seu titular" 42 . Possui "[...] alcance puramente formal, ou seja, visa a conseguir que o histórico registral de cada imóvel seja autêntico e completo, tomando-se necessária uma continuidade entre os lançamentos inerentes a esse mesmo imóvel" ${ }^{\prime 3}$. Extrai-se dos arts. 195, 237 (aspectos subjetivos) e do $\S 2^{\circ}$ do art. 225 (aspectos objetivos), todos da LRP.

O terceiro integrante da trinca é o princípio da especialidade, pelo qual "[...] toda inscrição deve recair sobre um objeto precisamente individuado" ${ }^{44}$. Deve ser observado no que respeita aos imóveis e às pessoas envolvidas, fato que se depreende do art. 176 da LRP.

De suas leituras, infere-se que os princípios, considerados estaticamente, voltamse a preservar o "direito individual" à propriedade privada. Todavia, quando a

\footnotetext{
${ }^{40}$ Malheiros (2019, p. 132-135).

${ }^{41}$ Carvalho (1976, p. 250-251).

${ }^{42}$ Carvalho (1976, p. 285).

${ }^{43}$ Melo (2010, p. 46).

${ }^{44}$ Carvalho (1976, p. 219).
} 
questão é estendida aos "direitos coletivos", deixam de atender à ordem jurídica em sua completude, demandando uma reinterpretação do sistema registral, que deve se harmonizar à função social da propriedade, não obstruindo a regularização. Esses juízos de ponderação encontram lastro, inclusive, nas diretrizes gerais do art. $2^{\underline{0}}$ do Estatuto da Cidade, sendo premissas à aplicação do instrumental pertinente à regularização fundiária de interesse social ${ }^{45}$.

A inaptidão referida pode ser mitigada caso se enfatizem outros princípios contidos na LRP, que permaneceram esquecidos por um longo tempo. Alude-se aos princípios da realidade, ou da verdade, e ao princípio da eficácia das vontades.

Quanto ao princípio da realidade, a interpretação que pode ser feita da verdade exigida pela $\mathrm{LRP}^{46}$ é que os registros exprimam os fatos, para que a descrição do livro imobiliário não seja apenas um desenho teórico das características do imóvel, correspondendo à realidade da sua "implantação" no solo, determinada por suas marcas e marcos. Assim, entre a realidade formal e a verdade física, a lei opta pela segunda: o sistema de registros não pode ficar alheio a seu objeto, que é a cidade como um todo ${ }^{47}$.

Já pelo princípio da eficácia das vontades, em consonância com o objetivo elencado no inc. V do art. 10 da Lei $\mathrm{n}^{\mathrm{o}} 13.465^{48}$, de 2017 , a LRP permite a alteração da informação do livro imobiliário a partir da pretensão das partes envolvidas, face à concordância de todos os confrontantes ${ }^{49}$, dando celeridade à resolução da questão, com redução (ou até eliminação) do formalismo judicial.

Tem-se, portanto, que

Os dois últimos princípios referidos confirmam que o sistema registral não é tão hermético quanto parece à primeira leitura, pois, visto de modo dinâmico, admite a substituição do errado pelo certo e que os titulares de direitos determinem, manifestando sua vontade, a modificação do desenho e da descrição registral. Assim,

\footnotetext{
${ }^{45}$ Malheiros (2019, p. 159).

${ }^{46}$ Art. 212. Se o registro ou a averbação for omissa, imprecisa ou não exprimir a verdade, a retificação será feita pelo Oficial do Registro de Imóveis competente, a requerimento do interessado, por meio do procedimento administrativo previsto no art. 213, facultado ao interessado requerer a retificação por meio de procedimento judicial.

${ }^{47}$ Salles (2007, p. 157).

${ }^{48}$ Art. 10 (omissis)

(...)

$\mathrm{V}$ - estimular a resolução extrajudicial de conflitos, em reforço à consensualidade e à cooperação entre Estado e sociedade;

${ }^{49}$ Art. 213 (omissis)

(...)

$\S 9^{\circ}$ Independentemente de retificação, dois ou mais confrontantes poderão, por meio de escritura pública, alterar ou estabelecer as divisas entre si e, se houver transferência de área, com o recolhimento do devido imposto de transmissão [...].
} 
quando a questão versar sobre regularização fundiária, as regras registrais devem atender à função social, prestigiando o coletivo em detrimento do individual ${ }^{50}$.

\section{Atuação da Corregedoria-Geral da Justiça paulista no âmbito da regularização fundiária urbana}

De logo, diga-se que a jurisdição não pode ter como escopo, somente, a solução de litígios. Deve visar, também, o esclarecimento à sociedade de que é possível ter acesso ao Direito de forma preventiva, evitando-se a lide, geradora de tensão no sistema jurídico.

Para tanto, o art. 236 da Constituição Federal, regulamentado pelo art. $1^{\mathrm{o}}$ da Lei no 8.935, de 1994, atribuiu ao Poder Judiciário o papel de regulador da atividade registral, abrangendo a organização dos serviços, sua regulamentação técnica e sua fiscalização ${ }^{51}$, assegurando aos usuários uniformidade de entendimentos e adequação aos fins colimados ${ }^{52}$. Atribuindo ao particular uma atividade de natureza pública, o Estado ocupa posição de garante do interesse coletivo através do exercício da regulação, conferindo máxima efetividade à lei.

Assim, buscando a via intermediária, assentam-se as duas funções que as "Normas" editadas pelo Poder Judiciário devem ter por objetivo atender:

A primeira delas seria a consolidativa, reunindo-se, em um só documento, (i) normas compulsórias dispersas no ordenamento jurídico e (ii) usos e costumes adotados de longa data na prática registral, muitas vezes confirmados pelas jurisprudências judicial e administrativa, que não se afastem das leis vigentes.

A segunda seria a edição, lege ferendi, de normas técnicas, fomentando qualidade e rapidez. Não se prestam, todavia, à "[...] enunciação de súmulas de jurisprudência, menos ainda de experimentações de novos entendimentos judiciais" [...]. Serviria, sim, a veicular a "verdadeira e prudente novidade", a que, face à variação das circunstâncias, preste-se a preservar a essência das instituições. Não se pode, assim, cogitar de se atentar à ontológica independência jurídica de magistrados e registradores ${ }^{53}$.

Nesse caminhar, como se disse, a Corregedoria-Geral da Justiça paulista aprovou, em 19/12/2017, seu Provimento CGJ no 51/2017, “considerando a entrada em vigor da Lei no 13.465/2017", inserindo os itens 273 a 330 nas Normas de Serviço

\footnotetext{
${ }^{50}$ Malheiros (2019, p. 160-161).

${ }^{51}$ Malheiros (2019, p. 141-156).

52 Ribeiro (2009, p. 07).

${ }^{53}$ Malheiros (2019, p. 156).
} 
paulistas ${ }^{54}$. Tentou-se simplificar, o quanto possível, as regras respeitantes ao programa, vez que "[...] do ponto de vista interpretativo, principalmente no aspecto formal da aplicação da legislação. Os operadores da regularização fundiária devem sempre ter em mente que regras e pensamentos inflexíveis são os principais entraves na regularização fundiária" ${ }^{\prime 5}$. Passa-se ao estudo de itens selecionados do Provimento, que dão ideia precisa do quanto exposto.

O item 274 dá o tom do Provimento: ao registrador cabe somente a "[...] realização do controle de legalidade meramente formal acerca das aprovações dos órgãos competentes". Refere-se, como dito, à "[...] constatação da obediência, ou não, aos atos administrativos de aprovação, às leis de regência, tão somente ao seu aspecto exterior". Já a "legalidade material do ato administrativo relaciona-se com o seu conteúdo [...]", sobre o qual o registrador não pode exercer controle ${ }^{56}$. Homenageia-se a presunção de legitimidade ${ }^{57}$ dos atos administrativos.

As funções supracitadas podem ser identificadas em inúmeros itens do Provimento. Por exemplo, o subitem 276.2, ao prever que o "indeferimento do registro do loteamento em uma circunscrição não determinará o cancelamento do registro procedido em outra, se o motivo do indeferimento naquela não se estender à área situada sob a competência desta", confere presteza ao procedimento da regularização fundiária, sem confrontar a legalidade. Nota-se, também, com mesmo móvel, exploração do potencial da Internet, sendo o caso do Item 279, que prescreve que a "CRF e os documentos que a compõem serão apresentados independentemente de requerimento e preferencialmente pela via eletrônica através da Central de Serviços Compartilhados dos Registradores".

O item 314 explora a interpretação sistemática do ordenamento jurídico em prol da função social da propriedade, robustecendo a realidade em detrimento do princípio da especialidade, dispondo que, quando "[...] a descrição do imóvel constante do título de transmissão for imperfeita em relação ao projeto de regularização fundiária registrado, mas não houver dúvida quanto à sua identificação [...], o interessado poderá requerer seu registro, de conformidade com a nova descrição". Doutrina sobre a Consolidação Normativa Notarial e Registral gaúcha, que possui regra similar, aduz que esta é "[...] viável, pois abrange a situação de alguns imóveis que são cortados por estradas e rodovias e estão

\footnotetext{
54 Malheiros (2019, p. 161-174).

${ }^{55}$ Melo (2010, p. 21).

${ }^{56}$ Fukassawa (2013, p. 115).

57 "Esse princípio, que alguns chamam de princípio da presunção de legalidade, abrange dois aspectos: de um lado, a presunção de verdade, que diz respeito à certeza dos fatos; de outro lado, a presunção da legalidade, pois, se a Administração Pública se submete à lei, presume-se, até prova em contrário, que todos os seus atos sejam verdadeiros e praticados com observância das normas legais pertinentes". (DI PIETRO, 2017, p. 139).
} 
pendentes dessas atualizações e averbações nas suas matrículas, as quais somente podem ocorrer com material elaborado por técnico competente $[\ldots]]^{\prime \prime 58}$.

O item 323, prescrevendo que o "interessado apresentará requerimento dirigido ao Oficial de Registro de Imóveis, instruído com os seguintes documentos: I anuência dos confrontantes da fração do imóvel que pretende localizar [...]; II - a identificação da fração, em conformidade com o projeto de REURB registrado, por meio de certidão atualizada expedida pelo Município", observa, respectivamente, os princípios da eficácia das vontades e da legalidade, privilegiando a realidade em detrimento do quanto consignado na matrícula.

Assim, já se disse que

Conforme se viu, as Normas de Serviço paulistas buscaram [...] evitar empecilhos à regularização fundiária. Desburocratizando procedimentos onde possível, simplificando exigências documentais, inclusive com dispensa de notificações desnecessárias, pretendeu-se contribuir ao atingimento concreto da função social da propriedade, integrando à cidade legal os loteamentos clandestinos ou irregulares, garantindo dignidade da fruição do direito de moradia aos beneficiários. O Provimento estudado se encontra alinhado à doutrina que entende que normas voltadas a concretizar demandas sociais devem estar abertas a novas interpretações conexas às mutações sociais, espaço, em regra, destinado à conformação do legislador e do administrador, não se podendo afastar, todavia, a possibilidade de atuação jurisdicional na concretização desses pleitos ${ }^{59}$.

\section{CONClUSÃo}

A Lei no 13.465, de 2017, que tratou da Regularização Fundiária Urbana (Reurb), definiu-a com uma acepção ampla e duas estritas, sendo uma destas relacionada à obtenção de títulos por parte dos moradores de onde se promovem os processos de regularização, face ao crescimento desordenado das grandes cidades brasileiras. Encontra substrato no art. $6^{\circ}$ da Constituição Federal, que positiva a moradia como direito social.

Tal política pública vem a reboque de um cenário que está se ampliando para a utilização de outros institutos jurídicos que não são propriedade stricto sensu, mas que se mostram mais viáveis, pois convivem com situações que impossibilitam ou dificultam a apropriação privada. Privilegia-se, pois, a função social da propriedade, estendendo seu alcance aos assentamentos informais.

${ }^{58}$ Gonsalves e Oliveira (2017, p. 251).

${ }^{59}$ Malheiros (2019, p. 174). 
Mesmo alvo de críticas doutrinárias e de ação direta de inconstitucionalidade, referida Lei se encontra em pleno vigor. Neste trabalho, foi analisada sob o prisma do "Quadro de Referência de Políticas Públicas", ferramenta apta a demarcar de modo cristalino os limites de determinado programa de ação, permitindo que o pesquisador "[...] possa se debruçar sobre poucas questões jurídicas selecionadas", abordando as políticas públicas com visão jurídico-institucional, rompendo com o isolamento metodológico do Direito.

Identificou-se como ponto merecedor de aprofundamento de estudo o sistema registral brasileiro, centrado nos princípios da legalidade, continuidade e especialidade, estaticamente interpretados, que não atendem aos princípios da regularização fundiária. Para tanto, devem ser tomados de modo dinâmico, sem comprometer sua segurança.

Avançou-se, então, rumo ao trabalho desenvolvido pela Corregedoria-Geral da Justiça paulista, em seu Provimento CGJ no 51, de 2017. Buscou-se, em âmbito administrativo, aumentar a efetividade da regularização, superando o foco de "direito individual" com que aqueles princípios são normalmente aplicados, evoluindo para uma mirada de "direito coletivo", com reinterpretação do sistema, resgatando os princípios da realidade e da eficácia das vontades.

Portanto, as Normas de Serviço paulistas buscaram evitar empecilhos à regularização fundiária. Desburocratizou procedimentos onde possível, contribuindo ao atingimento concreto da função social da propriedade, integrando à cidade legal os loteamentos clandestinos ou irregulares, garantindo dignidade da fruição do direito de moradia aos beneficiários.

Pretende-se, em próximos estudos, analisar os institutos e instrumentos utilizados para se alcançar a regularização, dependendo da tipologia da irregularidade; bem como em que medida quantitativa a nova legislação e a normatização administrativa logram realizar tal objetivo.

\section{REFERÊNCIAS}

ALFONSIN, Betânia de Moraes. O significado do estatuto da cidade para os processos de regularização fundiária no Brasil. In: ROLNIK, Raquel et. al. Regularização fundiária plena. Referências conceituais. Regularização fundiária sustentável - conceitos e diretrizes. Brasília: Ministério das Cidades, p. 68-99, 2007. Disponível em <http://www.capacidades.gov.br/biblioteca/detalhar/id/236 /titulo/regularizacao-fundiaria-plena >. Acesso em 25 abr. 2017.

BRASIL. Ministério das Cidades. Secretaria Nacional de Acessibilidade e Programas Urbanos. Departamento de Assuntos Fundiários Urbanos. Regularização fundiária urbana - MP 759/2016. 2017. Disponível em: 
$<$ legis.senado.leg.br/sdleg-getter/documento/download/cc2cbe30-44b8-4285-beb80e289618ad6d >. Acesso em 15 ago. 2018.

BUCCI, Maria Paula Dallari. Quadro de referência de uma política pública. Primeiras linhas de uma visão jurídico-institucional. 2015. Disponível em < https://www.researchgate.net/profile/Maria_Paula_Bucci/publication/301776630_ Quadro_de_referencia_de_uma_politica_publica/links/57275b0608aee491cb4141b b.pdf $>$. Acesso em 7 ago. 2019.

BUCCI, Maria Paula Dallari. Pesquisa em direito e políticas públicas. In: QUEIROZ, Rafael Mafei Rabelo; e FEFERBAUM, Marina (Orgs.). Pesquisa em direito: métodos, técnicas e abordagens. São Paulo: Saraiva, 2019 (no prelo).

CARVALHO, Afrânio de. Registro de imóveis. 3 ed. Rio de Janeiro: Forense, 1976.

CONSELHO DA JUSTIÇA FEDERAL. Enunciado no 492. Disponível em < http://www.cjf.jus.br/enunciados/enunciado/561 >. Acesso em 6 nov. 2018.

CONTROLADORIA-GERAL DA UNIÃO. Portal da Transparência. 2019. Acesso em 7 ago. 2019.

DI PIETRO, Maria Sylvia Zanella. Direito administrativo. 30 ed. rev., atual. e ampl. Rio de Janeiro: Forense, 2017.

D’OTTAVIANO, Maria Camila Loffredo; SILVA, Sérgio Luís Quaglia. Regularização fundiária no Brasil: velhas e novas questões. Planejamento e Políticas Públicas, v. 32, p. 201-229, 2009. Disponível em: $<$ http://www.ipea.gov.br/ppp/index.php/PPP/article/view/172/185 >. Acesso em: 11 fev. 2018.

FERNANDES, Edésio. Regularização de assentamentos informais na América Latina. Foco em políticas fundiárias. Lincoln Institute of Land Policy, 2011. Disponível em: $<$ https://www.lincolninst.edu/sites/default/files/pubfiles/regularizacaoassentamentos-informais-full_1.pdf >. Acesso em: 23 fev. 2018.

FUKASSAWA, Fernando. Regularização fundiária urbana: lei no 11.977/2009. São Paulo: Saraiva, 2013. 
FUNDAÇÃO JOÃO PINHEIRO. Déficit habitacional no Brasil 2015. Belo Horizonte: FJP, 2018. Disponível em:

<http://www.fjp.mg.gov.br/index.php/docman/direi-2018/estatistica-einformacoes/797-6-serie-estatistica-e-informacoes-deficit-habitacional-no-brasil2015/file >. Acesso em: 02 jul. 2018.

GONSALVES, Andressa Beschorner; OLIVEIRA, Patrícia Outeiral de. Dos institutos jurídicos da posse e da propriedade privada e a regularização do parcelamento e loteamento irregular ou clandestino do solo com base no provimento no 21/2011. Revista Direito, Cultura e Cidadania, v. 7, n. 1, 2017, p. 228-263.

HIRONAKA, Giselda Maria Fernandes Novaes. Tendências do Direito Civil no século XXI. FIUZA, César; SÁ, Maria de Fátima Freire de; NAVES, Bruno Torquato de Oliveira (Coords.). Direito civil: atualidades. Belo Horizonte: Del Rey, 2003.

LUFT, Rosangela Marina. Regularização fundiária de interesse social: a coordenação entre as políticas de urbanismo e de habitação social no Brasil à luz de experiências do direito francês. Tese em Cotutela (Doutorado). 2014. Universidade do Estado do Rio de Janeiro, Faculdade de Direito. Université Paris 1, Panthéon-Sorbonne, Faculté de Droit, 2014. Disponível em: $<$ http://www.bdtd.uerj.br/tde_busca/processaPesquisa.php?listaDetalhes\%5B\%5D $=5270 \&$ processar $=$ Processar $>$. Acesso em 6 abr. 2017.

MALHEIROS, Rafael Taranto. O procedimento administrativo da regularização fundiária urbana de interesse social como garantia do direito à moradia. Dissertação (Mestrado em Direito Político e Econômico). 2019. Orientadora: Clarice Seixas Duarte. Universidade Presbiteriana Mackenzie, São Paulo, 2019.

MELO, Marcelo Augusto Santana de. O direito à moradia e o papel do registro de imóveis na regularização fundiária. Revista de direito imobiliário, v. 69, 2010, p. 09-48.

MINISTÉRIO PÚBLICO FEDERAL. Petição na Ação Direta de Inconstitucionalidade no 5.771/DF - Distrito Federal, 2017. Disponível em: < http://www.mpf.mp.br/pgr/documentos/ADI5771regularizaofundiria.pdf $>$. Acesso em: 15 mar. 2018. 
PERLINGIERI, Pietro. O direito civil na legalidade constitucional. Trad. Maria Cristina de Cicco. Rio de Janeiro: Renovar, 2008.

PINTO, Victor Carvalho. Mitos e verdades sobre a nova lei da regularização fundiária urbana. 2017. Disponível em: < https://caosplanejado.com/mitos-everdades-sobre-a-nova-lei-da-regularizacao-fundiaria-urbana/ >. Acesso em: 17 mar. 2018.

RIBEIRO, Luís Paulo Aliende. Regulação da função pública notarial e de registro. São Paulo: Saraiva, 2009.

SALLES, Venício. Regularização fundiária. In: ROLNIK, Raquel et. al.

Regularização fundiária plena: referências conceituais. Brasília: Ministério das Cidades, 2007. Disponível em: <http://www.capacidades.gov.br/biblioteca /detalhar/id/236/titulo/regularizacao-fundiaria-plena>. Acesso em: 2 mar. 2018.

SAMORA, Patricia Rodrigues; HIRATA, Marcia Saeko. Habitação social e requalificação de áreas centrais após dez anos das ZEIS 3 de São Paulo. Anais do XV Encontro Nacional da ANPUR: Desenvolvimento, Planejamento e Governança. Recife, n. 689, p. 01-17, 2013.

SARLET, Ingo Wolfgang. Direito fundamental à moradia na constituição. Revista eletrônica sobre a reforma do Estado. Salvador, n. 20, 2009. Disponível em: $<$ http://www.direitodoestado.com.br/artigo/ingo-wolfgang-sarlet/o-direitofundamental-a-moradia-na-constituicao-algumas-anotacoes-a-respeito-de-seucontexto-conteudo-e-possivel-eficacia >. Acesso em: 12 fev. 2018.

SOTO, Hernando de. O mistério do capital - Por que o capitalismo dá certo nos países desenvolvidos e fracassa no resto do mundo. Trad. Zaida Maldonado. Rio de Janeiro: Record, 2001. 